\title{
Visitors' perceived trust in sincere, authentic, and memorable heritage experiences
}

\begin{abstract}
The success of cultural destinations often centres on whether consumers trust the provenance and integrity of the heritage assets, activities, and services therein. However, few studies examine whether this 'perceived trust' influences the authenticity, sincerity, and memorability of cultural heritage consumption. To investigate the relationships between these constructs, we surveyed 320 visitors to Iranian cultural heritage sites. The findings suggest that perceived trust positively influences visitors' perceptions of sincerity, existential authenticity, and object-based authenticity, stimulating memorable experiences in the process. This, in turn, emphasises the antecedent importance of perceived trust in shaping consumption. In the face of increasing commercialization within the cultural heritage sector more generally, we therefore encourage practitioners to prioritise safeguarding the integrity of their offerings, promoting heritage assets in a manner that stimulates perceived trust.
\end{abstract}

Keywords: Perceived trust; Sincerity; Authenticity; Memorable Tourism Experiences; Cultural Heritage; Iran

‘標題 : 遊客對真誠, 真實, 和難忘的文化遺產經驗的感知信任研究

摘要: 文化目的地的成功往往在於消費者是否信任文化遺產資產, 活動, 和服務。然而 , 很少有學者研究“感知信任”是否會影響文化遺產消費的真實性, 真誠性, 和可記憶 性。為了調查這些因素之間的關係, 我們調查了320名伊朗文化遺產所在地的訪客。調 查結果顯示, 感知信任對遊客對誠信, 存在真實性, 和基於對象的真實性的看法有正面 影響, 並且, 在此過程中, 會激發了難忘的經驗。因此更強調了感知信任對影響消費的 先行重要性。面對文化遺產觀光日益普遍的商業化, 我們因此鼓勵從業者優先考慮保 護其產品的完整性及真實性，以創造旅客感知信任的方式來促銷文化遺產資產。

關鍵詞：感知信任;誠意;真實性;難忘的旅遊經驗;文化遺產;伊朗 


\section{INTRODUCTION}

The crucial role that trust plays in shaping consumer behaviour is demonstrated across experiential consumption contexts. Accordingly, literature recognises the importance of perceived trust as a prerequisite to developing and maintaining enduring customer relationships and in stimulating consumer loyalty to brands, products, experiences, and services (Casielles, Álvarez, \& Martín, 2005). Consequently, perceived trust’s influence extends to the tourism industry, with its significance established within studies into: service provision (Lovell, 2009); destination management (Marinao Artigas et al., 2017); festival consumption (Gannon, Taheri \& Olya, 2019); booking intentions (Ponnapureddy et al., 2017); air travel (Deepa \& Jayaraman, 2017); and historical attractions (Curran et al., 2018).

However, despite these furtive moves towards developing greater understanding of perceived trust's role in shaping visitor experiences, it remains under-researched within the domain of cultural heritage consumption (Navrud \& Ready, 2002). This is somewhat surprising given the industry's emphasis on integrity, accuracy, and provenance; offering authentic experiences and objects to a visitor contingent eager to consume them, while simultaneously ensuring the preservation and conservation of heritage assets (MacKenzie \& Gannon, 2019). It is therefore crucial that visitors perceive a degree of trust in the heritage they choose to consume, both in terms of the authenticity of offerings, but also regarding industry leaders’ integrity in managing and protecting heritage assets (Lochrie, 2016).

To this end, satisfactory past visits remain the most obvious determinant of whether visitors perceive that they can trust heritage site offerings - simplifying and expediting the consumer decision-making process for future visits. However, destinations cannot rely solely upon repeat visitors, with many consumers visiting heritage sites for the first time, consuming new experiences with no first-hand information (Gannon et al., 2019). Given this potential ubiquity across different classifications of visitors, it is unsurprising that the concept of trust has received growing attention in relationship-oriented marketing discourse from practitioners and researchers alike. Here, it is established that perceived trust is a vital component of relationship-based communication, and that building trust is the ultimate goal of branding (Marinao Artigas et al., 2017). It may thus prove crucial for cultural heritage sites to ensure that their offerings appear trustworthy to potential visitors, with this prioritised when promoting assets therein (Tellström, Gustafsson, \& Mossberg, 2006). 
Indeed, while its importance in shaping decision-making is established (Bozic, 2017), prior studies into consumer trust typically focus on its antecedents (e.g., prior experiences, reputation) and consequences (e.g., loyalty, repurchase intentions). However, despite its role in engaging consumers within service settings, there remains little insight into how perceived trust can influence the relational consumer-service provider exchange (Lude \& Prügl, 2018). To this end, Lechner and Paul (2019, p.198) argue that "individuals experiencing positive affect are primed to evaluate observed behaviour in a more positive and trusting manner, whereas individuals in negative affective states interpret behaviour in a more sceptical way”. Further, research largely overlooks the importance of perceived trust in stimulating visitors' interest in cultural offerings (i.e., authentic heritage) and in sincere interactions with local inhabitants therein (Prince, 2017). This is again surprising given Gustafsson's (2005, p.523) suggestion that "authenticity primarily means being trustworthy, in the sense that [service providers] should act in-line with its brand values and behave as a citizen of the community" - a sentiment prevalent across the heritage sector (MacKenzie \& Gannon, 2019).

Meanwhile, authenticity and its associated concepts receive continued attention within the domain of cultural heritage consumption. For instance, the consumer-based model of authenticity (CBA) (Kolar \& Zabkar, 2010) has been adapted to acknowledge the importance of tangential variables, such as sincere interactions with local people, in stimulating memorable consumption (Taheri et al., 2018). However, couched within the CBA, research has yet to investigate the underlying importance of perceived trust in stimulating the authentic and sincere consumption crucial to memorable tourism experiences (MTE). Further, most studies focus on trust as a post-experience construct, with little known about how consumer trust influences on-site experiences. Thus, this study aims to address this gap by assessing the influence of perceived trust on authenticity (destination characteristics considered meaningful), sincerity (visitor-local interactions perceived as genuine), and subsequent MTE. We therefore examine whether visitors' 'perceived trust' influences 'perceptions of authenticity', 'sincerity' and 'MTE' within the context of cultural heritage consumption, irrespective of their status as first-time or repeat visitors.

\section{LITERATURE REVIEW}

The term 'heritage' refers to site, destination, or attraction characteristics that appeal to visitors' desire to consume experiences of natural, cultural, historical, or religious 
significance (Lochrie, 2016). Typically, heritage sites serve a dual-purpose, with emphasis placed on both preserving cultural assets and the economic benefit of visitor engagement with products and services therein. Heritage can be tangible or intangible (Rasoolimanesh et al., 2019), with the former including manmade and natural phenomena (e.g., architecture, museums, artefacts, and parks). Conversely, intangible heritage is more nebulous, encapsulating local culture and traditions, mythology, poetry, and literature. However, as reflected in this study, tangible and intangible heritage often co-exist, with this symbiosis labelled 'cultural heritage' (UNESCO, 2017). To this end, the value of cultural heritage to the tourism sector has rocketed in recent years, with international classifications (e.g., UNESCO World Heritage) thrusting many previously unknown sites firmly into the public eye (Lochrie, 2016).

Thus, while primarily underpinned by conservation, the pursuit of the economic bounty of increased visitor numbers has encouraged organisations across the sector to mould their offerings based on visitor expectations. However, industry managers must be careful when adapting cultural heritage, as this can lead to concerns surrounding authenticity. Here, consumer distrust is increasingly recognized as a serious marketplace concern (Enli \& Rosenberg, 2018), where balancing the challenge of providing suitably attractive and enjoyable experiences, underpinned by offerings perceived as authentic and sincere, remains a pervasive concern (Taheri et al., 2018). As such, in order to develop in a manner that stimulates memorable heritage consumption, it is crucial to identify whether perceived trust in sites and destinations influences visitor perceptions of the authenticity and sincerity of heritage offerings therein.

To this end, notions of trust underpin heritage consumption, as visitors seek assurance that the sites they visit are of true cultural significance (Curran et al., 2018). Visitors must therefore trust the integrity of heritage sites; it is crucial that they are not considered curated to a point where their authenticity is questionable. Further, as interactions with local people often underpin cultural heritage consumption, it is essential that visitors perceive these interactions as sincere and not exploitative (Taheri et al., 2018). In doing so, perceived trust may influence visitors' intentions to revisit destinations, sites, and attractions in future (Gannon et al., 2017).

\section{Perceived Trust and Trustworthiness}


Trust is not manifest in isolation, and is instead born from perceptions of multiple dimensions that together indicate the trustworthiness of an organisation, experience, or brand. This study therefore echoes extant literature in extricating trust from trustworthiness (Colquitt, Scott, \& LePine, 2007). To this end, literature demonstrates the nuanced differences in definitions of trust and trustworthiness across various academic disciplines (Table 1).

\section{[TABLE1]}

While Mayer, Davis and Schoorman's (1995) conceptualisation of trust may prove most relevant to this study, Table 1 reveals the significance of 'trust' across different contexts. Collectively, these studies highlight the ambiguity surrounding definitions of trust and trustworthiness, demonstrating the fragmented nature of current discourse (Dietz \& Den Hartog, 2006). In doing so, Table 1 demonstrates the importance of conceptualising trust and trustworthiness as multi-faceted, multi-referent, and multi-level concepts (Enli \& Rosenberg, 2018; Evans \& Krueger, 2009; Mayer et al., 1995). The multi-faceted and multi-referent nature of trust is evident between trustors and trustees via interpersonal exchanges (C2C) (Evans \& Krueger, 2009); inter-organisational exchanges (B2B) (Kroeger, 2012); and consumer-firm exchanges/relationships (C2B) (Sirdeshmukh et al., 2002). Trust is also a multi-level concept; organisational trust has been studied at the employee, team, organisational, and inter-organisational level (Fulmer \& Gelfand, 2012).

To this end, various models for trust development exist, with the calculus- or deterrence-based, knowledge-based, and identification-based models most relevant to this study. Calculus-based trust differs from identification-based trust; the former shapes marketbased exchanges, whereas the latter is concerned with relationship building (e.g., brand communities, loyalty programmes). Research suggests that calculus-based trust precedes knowledge-based trust; familiarity is required to develop knowledge-based trust because a trustor must first be familiar with the trustee. Trustors unfamiliar with trustees will rely on calculus-based trust, with knowledge-based trust stimulated via repeated exchanges and ongoing relationships. Over time, calculus-based trust turns into relational trust through repeated interaction (Rousseau et al., 1998). Relational trust can encourage affection between trustors and trustees, stimulating identification-based trust in the process.

Therefore, shared antecedents and consequences emerge across referents and levels of analysis (Fulmer \& Gelfand, 2012). Accordingly, the antecedent factors influencing perceived trust include ability (competence), benevolence, and integrity (Mayer et al., 1995; 
Sirdeshmukh et al., 2002). Shaped by consumer perceptions of organisational expertise, credibility, reliability, and dependability, ability refers to whether consumers believe that an organisation is capable of delivering its promised offering (Jin, Line, \& Merkebu, 2016). The importance of benevolence in shaping perceived trust emerges across various service domains, including restaurants (Jin et al., 2016), banks (Kantsperger \& Kunz, 2010), destinations (Marinao Artigas et al., 2017), and airlines (Sirdeshmukh et al., 2002). Thus, while perceived ability shapes MTE, perceived benevolence can also influence consumption outcomes (Kantsperger \& Kunz, 2010). Concerning integrity, consumers expect service providers to be honest in fulfilling their obligations, shaping perceived trust in the process (Ponnapureddy et al., 2017).

As such, Delgado-Ballester and Munuera-Alemán (2001, p.1242) consider brand trust "a feeling of security held by the consumer that the brand will meet his/her expectations". It is this notion that perceptions of whether a referent 'will' meet expectations, stimulating trust in the process, that suggests that trust can serve as an antecedent construct - manifest preconsumption, but only fully realised during or post-consumption (i.e., consumers' perceived trust in a product, service, or experience is only ratified or contradicted at the consumption stage). To this end, McKnight, Choudhury and Kacmar (2002) propose a 'trust-building model' (TBM), comprised of three phases: antecedents; beliefs and intentions; and trusting behaviours. The TBM is similar to the process of relationship development, where "trust is created by two antecedents (i.e., structural assurance and external factors) influencing consumers' trust intentions, which lead to engaging behaviors such as following advice, sharing information, and purchasing” (Yang et al., 2018, p.3). Thus, consumers may pursue the sense of security provided by experiences perceived as trustworthy (Fine, 2003), and are inclined to trust products or brands if they are confident that service providers can deliver on promises and meet their expectations (Napoli et al., 2014).

As such, there is a degree of consistency concerning scholarly emphasis on reliability (Sirdeshmukh et al., 2002), confidence (Moorman et al., 1992), and expectancy (Dietz \& Den Hartog, 2006) within multidisciplinary definitions of trust. This study therefore considers perceived trust within the cultural heritage context as when visitors have: "belief, trust or faith in an organization [i.e., a heritage site], its staff [i.e., the people they interact with] and services [i.e., the heritage assets therein]” (Flanagan, Johnston \& Talbot, 2005, p.375). Here, Flanagan et al. (2005) draw a distinction between service providers' ability to control or mould visitor expectations, suggesting trust may be shaped with or without prior 
consumption. For the former, organisations can influence consumer perceptions by meeting expectations previously whereas, for the latter, service providers may have little-to-no control over how trustworthy consumers perceive their offering to be. Thus, for consumers with no prior experience of a product, destination, or service, trust may be shaped by personal beliefs, the media, or via word-of-mouth - vessels difficult for organisations to control (Flanagan et al., 2005).

Nonetheless, perceived trust can be stimulated in other ways, underpinned by factors that organisations can control (e.g., visibility, familiarity, and communication). To this end, research demonstrates that repeat visitors display affective commitment and loyalty to organisations that have earned their trust (Bowden, 2009). Trust for first-time visitors, however, is yet to be earned, and new customers will be driven by calculative commitment when considering whether to engage or not with heritage sites (Flanagan et al., 2005). Further, heritage sites often rely on new consumers, as many visitors only do so once, particularly if they are tourists or do not live locally (Gannon et al., 2019). It is thus important for heritage sites to establish perceived trust (a positive calculative commitment) with potential new consumers via marketing communications.

Therefore, to motivate new consumers to visit cultural heritage sites, marketing communications must go beyond simply creating awareness and recognition. First-time visitors may be sceptical and pose challenging questions such as "I need to trust what you say is what you deliver” (Lane, 2007, p.249). This can solidify visitor expectations and will likely mould their perceptions of the cultural heritage site's 'brand promise'. However, marketing communications do not deliver the brand promise - this is contingent on the service process. Cultural heritage sites must thus provide MTE during consumption. Disappointment, especially at the beginning of consumption experiences, may raise concerns regarding organisational competence and trigger visitor distrust (Enli \& Rosenberg, 2018). As such, perceived trust may serve as an important determinant of consumption - visitors' perceptions of whether an experience is trustworthy are likely to shape their experiences, with perceptions of trustworthiness influencing decision-making in both affective and cognitive terms, guiding behaviour pre-, during, and post-consumption.

Cultural heritage sites therefore represent the 'referent' (one who is being trusted) within this study (Dietz \& Den Hartog, 2006), with focus placed on visitors' perceived trust of these sites. Here, perceived trust is conceptualised based on four attributes (dependability, 
competence, integrity, and responsiveness) (Sirdeshmukh et al., 2002). Further, as perceived trust is self-identified by visitors based on whether they believe an experience is trustworthy or not, data was collected on-site. Therefore, the conceptualisation of trust employed within this study echoes calculus-based trust, underpinned by "confident positive expectations" (Dietz \& Den Hartog, 2006, p.564).

\section{Cultural Heritage Characteristics: Sincerity and Authenticity}

One significant debate in contemporary marketing and branding research centres on brand heritage, its antecedents (e.g., familiarity, nostalgia), and its consequences (e.g., loyalty, attachment) (Rose et al., 2016). A brand's link to the past constitutes its 'brand heritage', which acts as an asset for trust building. A brand with provenance, stability, and authenticity is typically considered 'strong' - stimulating perceived consumer trust, and inspiring memorable experiences (Merchant \& Rose, 2013).

Regarding cultural heritage consumption, attributes contributing to the authenticity or sincerity of destinations and attractions dominate discourse on how trustworthy offerings therein are perceived to be (Kolar \& Zabkar, 2010). However, the perceived sincerity of locals and their impact on experiential consumption is often overlooked (Prince, 2017). Interactions with local people are an important aspect of destination personality, and can encourage leisure consumption (Taheri et al., 2018). However, this is only manifest if visitors trust that interactions are likely to be sincere and provide an accurate representation of life at a cultural place (Wang et al., 2014). Two distinct yet complementary dimensions underpin this host sincerity: 'sincere social interactions' and 'sincere emotional responses' (Taheri et al., 2018). Social interactions are considered sincere when locals willingly provide visitors with insight into their lives, not solely for financial reward (Prince, 2017). Visitors' sincere emotional response acknowledges that these interactions occur, focussing on the emotional impact of this local-visitor interface (Taheri et al., 2018). This suggests that if visitors trust the integrity of their interactions with locals, concerns surrounding the sincerity of these interactions may be diluted.

Therefore, consumers' perceptions of sincere consumption experiences are driven by the actions of locals, where passion, openness, and integrity are married together with a desire to represent local culture and values (Wang, Ngamsiriudom, \& Hsieh, 2015). Locals’ behaviours should be place-specific, culture-sensitive, manifest irrespective of visitor presence, and natural (Prince, 2017). As such, perceived trust may influence visitors' 
attitudes towards whether their interactions with locals are sincere, with little careful curation, management, or cynicism (Taheri et al., 2018). Thus:

H1: Perceived trust is positively related to sincerity.

Visitor-local interactions are not the only elements of cultural heritage consumption likely to be influenced by perceived trust. While debate remains concerning its exact characteristics, the desire to experience authentic heritage has long-motivated consumption (Curran et al., 2018). Authenticity research often prioritizes two elements: object-based and existential authenticity (Taheri et al., 2018). Object-based authenticity encompasses "how people see themselves in relation to objects" (Steiner \& Reisinger, 2006, p.74) and is concerned with visitors' perceptions of tangible heritage assets encountered in-situ. If these objects are considered appropriately native, and visitors trust their provenance, they may contribute to the overall perceived authenticity of such sites (Kolar \& Zabkar, 2010).

However, cultural heritage consumption is inherently experiential and native objects do not exist in isolation. Authenticity can thus also be derived from visitors' 'lived experience' (Taheri et al., 2018). This is both intra-personal (physical) and inter-personal (self-made) in nature, where involvement, engagement, and participation in activities perceived to be authentic can stimulate positive emotional responses (Gannon et al., 2017). These elements should be distinct and novel, yet fulfilling and gratifying (Steiner \& Reisinger, 2006). However, cultural heritage consumption is rarely context or object-free, and thus both components often emerge harmoniously, where on-site artefacts positively influence the perceived authenticity of cultural heritage sites as a whole (Ye, Xiao, \& Zhou, 2018).

Moreover, consumers typically place greater faith and trust in sites that they expect to house authentic heritage from which they can derive value (Lude \& Prügl, 2018). Studies indicate that consumers' perceptions of authenticity and trust are conceptually different; however, there is a positive relationship between both (Napoli et al., 2014). Taheri et al. (2018) argue that antecedent factors (e.g., cultural motivations, trust) may influence the perceived authenticity and sincerity of cultural places. As such, both sincerity and authenticity are likely to be underpinned by visitors’ perceptions of how trustworthy a site’s offering is likely to be; trust in the provenance of the consumption experience and objects 
therein, and trust that locals are likely to act in a sincere - not disingenuous - manner. Therefore:

H2: Perceived trust is positively related to object-based authenticity.

H3: Perceived trust is positively related to existential authenticity.

H4: Object-based authenticity is positively related to existential authenticity.

\section{Memorable Tourism Experiences}

Cultural heritage site managers aiming to build enduring and successful offerings strive to provide visitors with experiences that are exciting, distinct, and ultimately memorable (Yalinay et al., 2018). Trust in consuming experiences has been conceptualized as 'experiential trust' (Wu, 2017), serving as a core dimension of the consumer experience index (Knutson et al., 2011). If visitors' perceive they can trust the sincerity of locals, the authenticity of objects found at destinations, and the authenticity of consumption experiences as a whole, this might stimulate MTE (Kolar \& Zabkar, 2010; Prince, 2017). This memorability is also influenced by perceptions of destination and attraction quality, and the satisfaction derived from consumption therein (Yalinay et al., 2018). Contingent on both the emotional and sensory experiences, it can encourage visitors to revisit cultural places, or to recommend them to others (Thompson et al., 2018). As such, a cultural heritage site's tangible and intangible characteristics contribute significantly to MTE, doing so with a degree of synchronicity (Lee, 2015). As visitors increasingly pursue opportunities to engage with authentic objects (Kolar \& Zabkar, 2010), interact with sincere locals (Wang et al., 2015), and foster experiential emotional connections (Gannon et al., 2017), heritage consumption perceived as trustworthy while satisfying each of these expectations may emerge as more memorable (Lude \& Prügl, 2018). Thus:

H5: Perceived trust positively influences MTE.

H6: Host sincerity positively influences MTE.

H7: Object-based authenticity positively influences MTE.

H8: Existential authenticity positively influences MTE.

\section{RESEARCH METHOD}




\section{Data Collection}

Face-to-face questionnaires were employed to collect data from visitors at five heritage sites (Amir Nezam House; Blue Mosque; Boulourchian house; Constitutional House of Tabriz; Ghari Bridge) in Tabriz, Iran in 2017. A celebrated cultural destination, Tabriz is home to many internationally recognised heritage assets. However, it is perhaps best known for its marketplace complex, which has served as a pillar of the Silk Road since the $13^{\text {th }}$ century and remains a globally recognised example of a traditional bazaar (Curran et al., 2018).

We explained the purpose of this study to willing participants, and pilot tested it with 25 heritage site visitors. The questionnaire was converted to Farsi then 'back-translated' into English to validate the meaning of each question (Gannon et al., 2017). From here, questions were modified and 320 responses comprising the final sample were collected. The mean replacement technique was used to overcome missing values across the dataset (Hair, Black, Babin, \& Anderson, 2010). Demographically, 53.2\% of the participants were male, with $57.1 \%$ aged $46+$. Further, $38.8 \%$ were local to Tabriz, with the rest from elsewhere in Iran.

\section{Measures and Common Method Variance}

All measures were adapted from prior studies, with statements answered on a 7-point Likert scale (1 'strongly disagree'; 7 'strongly agree'). Items from Kolar and Zabkar (2010) and Bryce et al. (2015) measured object-based authenticity. Six items, also adapted from Kolar and Zabkar (2010), measured existential authenticity, with MTE measured via five items adapted from Lee (2015). Sincerity, a multi-dimensional concept underpinned by two dimensions (sincere social interaction and sincere emotional response), was measured using a 10-item construct introduced by Taheri et al. (2018). Table 2 provides an overview of these constructs, their underlying items, and descriptive statistics.

Consistent with extant studies, we followed the behavioural definition of trust (Mayer et al., 1995; Sirdeshmukh et al., 2002) to capture respondents' perceived trust of heritage offerings within Tabriz. Sirdeshmukh et al., (2002, p.17) define trust as “...the expectations held by the consumer that the service provider is dependable and can be relied on to deliver on its promises”. Sirdeshmukh et al. (2002) and Mayer et al. (1995) also highlight the main characteristics of a trustee based on previous studies: ability (competence), benevolence, and integrity. As such, perceived trust was measured using four items adapted from Sirdeshmukh et al. (2002). The instruction provided to respondents was - "based on your past experience 
with other heritage sites, please evaluate your experience with locals and heritage sites in Tabriz”. Perceived trust was then measured based on participants' responses to the following: 'I feel that this heritage site is': (i) “1 'very undependable' to 7 'very dependable’; (ii) “1 'very incompetent' to 7 'very competent'”; (iii) “1 'of very low integrity' to 7 'of very high integrity””; and (iv) “1 'very unresponsive to visitors' to 7 'very responsive to visitors””. As with the items used to measure authenticity, sincerity, and MTE, a 7-point Likert scale was employed.

We also tested for the presence of Common Method Variance (CMV). To minimise social desirability bias, participants were informed that all answers would remain anonymous. Independent and dependent constructs were placed in different parts of the questionnaire. Two statistical approaches were used to evaluate CMV. First, Harman's single-factor test was employed by entering all principal constructs into a Principal Component Analysis (PCA) (Podsakoff et al., 2003). The eigenvalue unrotated PCA solution detected 7 factors, with the highest portion of variance explained by a single factor $32.211 \%$. Second, the unmeasured method factor approach was employed, with a common method factor presented to the structural model (Liang et al., 2007). We calculated average variance of indicators and the method factor, with results indicating that the average variance illustrated by indicators was $61 \%$, whereas the average method-based variance was 1.6\% (38:1). Therefore, CMV was not a concern.

\section{[TABLE2]}

\section{Empirical Analysis}

Partial Least Square structural equation modeling (PLS-SEM) was used to test the conceptual model. PLS-SEM is appropriate for examining formative, reflective, composite and higherorder models (Henseler, Ray, \& Hubona, 2016). Advancing conventional PLS-SEM, Consistent Partial Least Squares (PLSc) was employed for the estimation and assessment of the model (Dijkstra \& Henseler, 2015). PLSc "solves the consistency problem, path coefficients, construct correlations, and indicator loadings...avoids the issue of overestimation and underestimation of parameters" (Liébana-Cabanillaset al., 2017, p.1020). PLS-SEM uses a bootstrapping approach to test the consistency of estimates, and is an established variance-based SEM technique employed across service and tourism literature (Taheri, Jafari, \& Okumus, 2017). ADANCO 2.0.1 variance-based software was used to 
examine the conceptual model by running the bootstrapping algorithm with 5,000 resamples (Henseler, 2017)

\section{Measurement Model Evaluation}

Echoing Ajamieh et al. (2016), we evaluated measurement model reliability and validity. As per Table 3, all first-order reflective constructs held adequate internal consistency, alongside convergent and discriminant validity. Thus, the reflective constructs can be regarded unidimensional. To test whether the first-order reflective constructs differed sufficiently, we examined their discriminant validity using Fornell and Larcker's (1981) criterion, which requires a construct's AVE to exceed the square of its largest correlation with any other construct. All reflective constructs met this requirement (Table 4). Following Henseler, Ringle, and Sarstedt (2015), we also tested for heterotrait-monotrait ratio of correlations (HTMT). HTMT offers superior performance by means of a Monte Carlo simulation when compared to Fornell and Larcker's (1981) criterion. All HTMT values were <.85. Thus, discriminant validity exists between constructs (Table 4).

\section{[TABLE3]}

\section{[TABLE4]}

To examine the second-order factor structure, the repeated measures approach was used to estimate hierarchal component models (HCMs) in PLS-SEM (Ajamieh et al., 2016). The relationships between the second-order 'host sincerity' construct and its two underlying factors: (1)sincere social interaction $\left(\beta=.85 ; t\right.$-value $\left.=51.01 ; \mathrm{R}^{2}=.83\right)$ and (2)sincere emotional response $\left(\beta=.83\right.$; $t$-value $\left.=38.78 ; \mathrm{R}^{2}=.78\right)$ were significant. Further, all $\mathrm{R}^{2}$ values surpassed the recommended threshold (.50). Finally, we established multicollinearity among items by employing the variance inflation factor (VIF) and tolerance test. All VIF values were below the threshold (>3) and the tolerance test reported a value of <0.31 (Hair et al., 2010). Therefore, multicollinearity was not a concern (Table 3).

\section{Hypotheses Testing}

Goodness-of-Fit was supported by two approximate measures: a standardized root mean square residual (SRMR) of .057 for PLS and .052 for PLSc (acceptable if SRMR<.08) (Hair et al., 2017). Figure 1 presents the outcome of the PLS-SEM by means of its $\mathrm{R}^{2}$ and $\beta$-value for both PLS and PLSc models, with consistent results. As per Figure 1, and confirming H1, the results demonstrate that perceived trust has a positive impact on sincerity. The results also 
revealed a positive relationship between perceived trust and object-based authenticity, confirming H2. Further, the results indicate a positive relationship between perceived trust and existential authenticity, supporting H3. As per H4, the results suggest that there is a positive relationship between object-based authenticity and existential authenticity. Confirming $\mathbf{H 5}$ and H6, a direct positive relationship was found between (a) perceived trust and, (b) sincerity, and MTE respectively. Finally, existential authenticity exerted positive effects on MTE, confirming H8. However, the results rejected the proposed relationship between object-based authenticity and MTE (H7). Following Yalinay et al. (2018), the correlations between each dimension of the higher order sincerity construct and related constructs (i.e., perceived trust and MTE) were tested. The results confirm the positive relationships between perceived trust, MTE and the two underlying sincerity dimensions (Table 5).

\section{[FIGURE1]}

\section{[TABLE5]}

\section{Post-hoc Analysis of Indirect Effects}

Following Taheri et al. (2017), we conducted further mediation analyses via the bootstrapping method. Using a 95\% confidence interval (CI) for the parameter estimates, resampling 5,000 times, the results indicate the indirect effect of perceived trust on existential authenticity through object-based authenticity (indirect $\beta=.41, t$-value=15.11, $p<.001,95 \%$ $\mathrm{CI}=[.40, .43])$. As the direct effect of this relationship was also significant, the results suggest that object-based authenticity partially mediates the influence of perceived trust on existential authenticity. The findings also indicated the indirect effect of perceived trust on MTE through sincerity (indirect $\beta=.37, t$-value $=12.13, p<.001,95 \% \mathrm{CI}=[.33, .43]$ ). Again, as the direct effect was significant, sincerity partially mediates the influence of perceived trust on MTE.

\section{DISCUSSION AND IMPLICATIONS}

We examined whether visitors' 'perceived trust' influences their perceptions of authenticity, sincerity, and MTE at heritage sites. The findings first establish the significant influence of perceived trust on sincerity (H1), object-based authenticity (H2), and existential authenticity (H3). Thus, this study provides evidence that perceived trust can influence how visitors perceive locals (perceptions of social interactions and subsequent emotional responses) and 
heritage sites/assets (object-based authenticity, existential authenticity), consistent with previous studies (Curran et al., 2018; Taheri, et al., 2018; Wang et al., 2014). Further, objectbased authenticity was positively related to existential authenticity within this heritage consumption context (H4), echoing extant discourse (Bryce et al., 2015; Taheri et al., 2018).

Moreover, the results indicate that its antecedents (including sincerity, existential authenticity, and perceived trust) influence MTE (H5, H6, H8). This is consistent with Wang et al. (2014), Bryce et al. (2015), and Taheri et al. (2018), who also highlight the importance of trustworthiness, host sincerity, and authenticity on MTE. However, the results identified no significant relationship between object-based authenticity and MTE (H7), which challenges established understanding of the interplay between these often-complementary constructs (cf. Bryce et al., 2015; Kolar \& Zabkar, 2010). Therefore, this study contributes to extant discourse by demonstrating the nuanced impact of perceived trust on cultural heritage visitors' perceptions of host sincerity, authenticity, and MTE (Bozic, 2017; Taheri et al., 2018).

\section{Theoretical Implications}

This study contributes to ongoing theorising on relationship marketing within tourism literature by further investigating factors influencing consumer decision-making, attitudes, and evaluations within the cultural heritage context. The findings contribute to our understanding of perceived trust and provide a basis for predictors of MTE. One of the more noteworthy findings, in contrast to extant discourse, suggests that object-based authenticity is not considered a predictor of MTE (cf. Gannon et al., 2017). This is a significant counterpoint to existing knowledge within the field of consumer research, where the importance of artefacts found at cultural places has often been considered paramount (Curran et al., 2018; Kolar \& Zabkar, 2010; Taheri et al., 2018). Further, this study extends extant knowledge of trust as an antecedent construct, with the power to influence visitor perceptions during consumption. The principal theoretical implication is therefore that perceived trust plays an important role in shaping memorable visitor experiences. This suggests that visitors are likely to have an opinion on whether they trust the integrity of a heritage offering, and that this can influence their perceptions of tangible, intangible, and experiential stimuli on-site (e.g., perceptions of authenticity and sincerity), and resultant post-consumption outcomes (e.g., MTE). As such, the relevance of perceived trust is supported in relation to object-based authenticity, existential authenticity, sincerity, and MTE. The study therefore extends extant understanding of the role of perceived trust within the context of cultural heritage 
consumption - serving as a core psychological need that can be satisfied at multiple points throughout the process (Wang et al., 2014).

Thus, the results demonstrate that perceived trust plays an important antecedent role, with the power to influence visitor experiences and brand loyalty. This suggests that perceived trust serves to underpin cultural heritage sites' brand equity as visitors' perceptions of the potential value delivered on-site can encourage calculus-based trust (of potential relevance to first-time visitors) or commitment and loyalty through knowledge- or identification-based trust (of potential relevance to repeat visitors). As such, while this study did not examine differences between groups, it is important to acknowledge that perceived trust may act differently for both new and repeat visitors, in line with extant literature (Gannon et al., 2019). Nonetheless, the findings suggest that perceived trust is likely to play a crucial role in stimulating memorable cultural heritage consumption for visitors irrespective of prior on-site experience.

\section{Practical Implications}

Vital to relationship marketing within the cultural heritage sector, perceived trust can “dismiss customers' vulnerability during their decision-making process when they are in an uncertain environment” (Wang et al., 2014, p.6). The heritage industry is underpinned by uncertainty, particularly for first-time visitors (Gannon et al., 2019). Thus, site managers should design their marketing activities in a way that demonstrates the trustworthiness of their offerings by developing strategies aimed at ensuring perceived authenticity and sincerity, building consumer trust in the process. As such, this study provides insight into how cultural heritage sites can systematically work to nurture consumer trust through positive associations with the site's competence and locals' behaviours and attitudes. Both the site itself and the local people are therefore essential for building authenticity and sincerity-based perceived trust.

Nonetheless, the process of earning trust can be slow, but distrust can emerge rapidly and with significant consequences (Enli \& Rosenberg, 2018). Thus, the findings suggest that this process should be carefully managed, ensuring that all visitors receive excellent service on-site. Service management theory postulates that delivering 'promises' within the service environment nourishes 'trust', while dealing well with perceived problems avoids triggering consumer 'distrust'. Thus, to stimulate perceived trust, cultural heritage site managers should opt to develop and subsequently draw upon their site’s social currency. Social currency refers 
to brand-specific interactions manifest in offline and online platforms and, as per Kesgin and Murthy (2019), higher perceived social currency can enhance brand equity, improves experience quality, engenders trust, and stimulates consumer loyalty.

Thus, while cultural heritage visitors are typically motivated by a desire to experience genuine local culture in a meaningful manner, the commercialisation and modernisation of cultural places can undermine the perceived authenticity and sincerity of such offerings (Taheri et al., 2018). Cultural heritage visitors may become cautious and distrustful if they consider that the 'real' experience has been manipulated with profit solely in-mind. Therefore, perceived trust plays a key, underlying role in shaping visitor perceptions, encouraging them to feel that they are likely to gain a 'real' experience through both objects/experiences felt to be meaningful (authenticity) and interactions with locals perceived to meaningful (sincerity) at cultural heritage sites.

Regarding authenticity, our findings suggest that greater effort is required to improve perceptions of object-based authenticity at heritage sites (e.g., tweaking the presentation of native objects, site design, and layout) in order to meet visitor expectations. More specifically, our sample demonstrated lower mean scores (Table 2) for the four object-based authenticity underlying items. This reflects competence-based perceived trust in the policies and procedures of the cultural sites. Second, ensuring appropriate experience design, services, and support should also be considered a priority for site managers hoping to stimulate perceived existential authenticity. This may enhance perceived competence; stimulating perceived trust while reducing the potential for distrust to emerge. Thus, managers must design servicescapes with the intent of evoking desired emotions in visitors' minds throughout their on-site journey (Yalinay et al., 2018). There is therefore a need to design heritage site servicescapes in a manner that encourages local-visitor exchanges during consumption, stimulating sincere social interactions and sincere emotional responses.

Therefore, the cultural heritage industry must take advantage of their 'setting' (e.g., servicescape) by placing visitors at the centre of experience management processes. In doing so, social connectivity (Gannon et al., 2017), participatory engagement (Simon, 2010), and social currency (Kesgin \& Murthy, 2019) may emerge as useful tools, aiding managers in the curation of on-site experience management processes. This could offset prior over-reliance on transaction-based exchanges, moving the sector towards a relationship-based model. In doing so, participatory engagement could serve to stimulate social connectivity, facilitating 
interactions on-site, in line with extant research which promotes cultural heritage sites as “important hubs that elevate sociability” (Jafari, Taheri, \& vom Lehn, 2013, p.1746). To this end, the industry should embrace Simon's (2010) suggestions on participatory and interactive design in order to stimulate visitor-visitor interactions and meaningful exchanges (Cordina, Gannon \& Croall, 2019).

Further, this study suggests that perceived trust could reassure visitors that cultural heritage consumption will be memorable. This is of particular importance as it can be used to develop targeted interventions aimed at new visitors. For new visitors, perceived trust is crucial, as their ability to process information is likely to differ significantly from those of repeat visitors (cf. Gannon et al., 2019) Further, perceived trust can lead to rapport between individuals, stimulating cooperation (Lovell, 2009). Managerial atteantion should therefore centre on establishing perceived trust between visitors and locals so in order to encourage cocreation. In order to do so, the consumer experience should be designed in a manner that facilitates high quality, sincere visitor-local interactions, with multiple interactive touchpoints along the way (Taheri et al., 2018). This may help to develop cognitive commitment in new visitors and affective commitment in repeat visitors, who may consequently serve as brand advocates.

The way in which visitors connect with destinations, sites and attractions continues to change. This influences how industry managers and marketers develop relationships with potential visitors. Nonetheless, technology can help the cultural heritage industry build and maintain close relationships with visitors. Thus, the findings suggest that there is potential for cultural heritage sites to move away from the traditional 'object-based exchange' towards a dialogue-based, relational exchange. In doing so, site managers must ensure that objects are used to support engaging, inventive, and meaningful host-visitor and visitor-visitor interactions, echoing the relationship between object-based authenticity and MTE identified within this study (Lochrie et al., 2019). For example, developing an open, international, and responsive online presence may allow industry managers to benefit from the advocacy behaviour inherent within online brand communities (Hewer et al., 2017), further developing the potential for visitors to trust the provenance and integrity of their offering. More specifically, visitor engagement may increase if marketers demonstrate that their offering is characterised by authentic and sincere values. Thus, care should be taken in designing and presenting the characteristics of heritage sites in a promotional capacity. 
The findings also recognize the wider societal impact of established or earned trust and cultural heritage consumption. As, Simintiras et al. (2014) remind us, confidence and trust research can contribute significantly at macro and micro levels. Visitors, locals, and cultural heritage site managers may benefit from satisfactory consumption experiences; satisfactory heritage consumption is likely to be memorable and may enhance the wellbeing of visitors, which in turn can positively affect the community in which cultural heritage sites are located.

\section{Limitations and Future Research}

Finally, we recognize the limitations of this study. First, the results are contextually restricted as all data was collected from one Iranian city. While Iran is experiencing increasing tourist attention (Taheri et al., 2019) the antecedent importance of perceived trust may be lower for individuals visiting established heritage sites in developed markets. We therefore encourage colleagues to explore the relationships between perceived trust, sincerity, authenticity, and MTE in alternate contexts, comparing their findings accordingly. Second, this is a crosssectional study. Thus, the broad confirmation of causal predictions is constrained by design. Further, questionnaires alone were employed to collect data. While emphasis was placed on ensuring the validity of this approach, supplementary qualitative data could help to explore the interplay between the constructs central to this study. We therefore encourage future research to collect qualitative interview data and in-depth, descriptive visitor accounts of how perceived trust, authenticity, and sincerity can foster memorable heritage consumption. Finally, extant literature (Flanagan et al., 2005; Gannon et al., 2019) suggests that perceived trust may be manifest differently for different consumer groups (e.g., for first-time/repeat visitors or domestic/international visitors). Thus, future research could focus on identifying differences in the antecedent role that trust plays in shaping consumption between diverse visitor groups within the context of cultural heritage tourism. Nevertheless, these limitations provide opportunities for colleagues to extend this nascent study into the importance of perceived trust, sincerity, and authenticity in stimulating memorable experiences within the context of cultural heritage consumption. 


\section{REFERENCES}

Ajamieh, A., Benitez, J., Braojos, J., \& Gelhard, C. (2016). IT infrastructure and competitive aggressiveness in explaining and predicting performance. Journal of Business Research, 69(10), 4667-4674.

Al Qundus, J., Paschke, A., Kumar, S., \& Gupta, S. (2019). Calculating trust in domain analysis: Theoretical trust model. International Journal of Information Management, 48, 1-11.

Bowden, J.L.H. (2009). The process of customer engagement: A conceptual framework. Journal of Marketing Theory and Practice, 17(1), 63-74.

Bozic, B. (2017). Consumer trust repair: A critical literature review. European Management Journal, 35(4), 538-547.

Bryce, D., Curran, R., O’Gorman, K., \& Taheri, B. (2015). Visitors' engagement and authenticity: Japanese heritage consumption. Tourism Management, 46, 571-581.

Casielles, R.V., Álvarez, L.S., \& Martín, A.M.D. (2005). Trust as a key factor in successful relationships between consumers and retail service providers. Service Industries Journal, 25(1), 83-101.

Caton, S., Dukat, C., Grenz, T., Haas, C., Pfadenhauer, M., \& Weinhardt, C. (2012). Foundations of trust: Contextualising trust in social clouds. 2012 Second International Conference on Cloud and Green Computing, 424-429.

Colquitt, J.A., Scott, B.A., \& LePine, J.A. (2007). Trust, trustworthiness, and trust propensity: A meta-analytic test of their unique relationships with risk taking and job performance. Journal of Applied Psychology, 92(4), 909-927.

Cordina, R., Gannon, M.J., \& Croall, R. (2019). Over and over: Local fans and spectator sport tourist engagement. Service Industries Journal, 39(7-8), 590-608.

Curran, R., Baxter, I.W.F., Collinson, E.,...\& Yalinay, O. (2018). The traditional marketplace: serious leisure and recommending authentic travel. Service Industries Journal, 38(15-16), 11161132.

Deepa, M.V., \& Jayaraman, K. (2017). Scale measurements for airline service quality to secure passenger confidence in air travel. The Quality Management Journal; Milwaukee, 24(3), 3153.

Delgado-Ballester, E., \& Luis Munuera-Alemán, J. (2001). Brand trust in the context of consumer loyalty. European Journal of Marketing, 35(11/12), 1238-1258.

Dietz, G., \& Den Hartog, D.N. (2006). Measuring trust inside organisations. Personnel Review, 35(5), 557-588.

Dijkstra, T. K., \& Henseler, J. (2015). Consistent partial least squares path modeling. MIS Quarterly, 39(2), 297-316.

Enli, G., \& Rosenberg, L.T. (2018). Trust in the age of social media: Populist politicians seem more authentic. Social Media + Society, 4(1), 1-11.

Evans, A.M., \& Krueger, J.I. (2009). The psychology (and economics) of trust. Social and Personality Psychology Compass, 3(6), 1003-1017.

Fine, G.A. (2003). Crafting authenticity: The validation of identity in self-taught art. Theory and Society, 32(2), 153-180.

Flanagan, P., Johnston, R., \& Talbot, D. (2005). Customer confidence: the development of a "preexperience” concept. International Journal of Service Industry Management, 16(4), 373-384.

Fornell, C., \& Larcker, D. F. (1981). Structural equation models with unobservable variables and measurement error: Algebra and statistics. Journal of Marketing Research, 18(3), 382-388.

Fulmer, C.A., \& Gelfand, M.J. (2012). At what level (and in whom) we trust: Trust across multiple organizational levels. Journal of Management, 38(4), 1167-1230.

Gannon, M.J., Baxter, I.W.F., Collinson, E.,...\& Yalinay, O. (2017). Travelling for Umrah: destination attributes, destination image, and post-travel intentions. Service Industries Journal, 37(7-8), 448-465.

Gannon, M., Taheri, B., \& Olya, H. (2019). Festival quality, self-connection, and bragging. Annals of Tourism Research, 76, 239-252. 
Gidman, W., Ward, P., \& McGregor, L. (2012). Understanding public trust in services provided by community pharmacists relative to those provided by general practitioners: a qualitative study. BMJ Open, 2(3).

Gustafsson, G. (2005). Brand trust and authenticity: The link between trust in brands and the consumer's role on the market. In K. M. Ekstrom \& H. Brembeck (Eds.), European Advances in Consumer Research (Vol.7, pp.522-527). Goteborg, Sweden:ACR.

Hair, J.F.J., Black, W.C., Babin, B.J., \& Anderson, R.E. (2010). Multivariate data analysis: A global perspective. Upper Saddle River, NJ, USA: Pearson Education.

Henseler, J. (2017). ADANCO2.0.1. Retrieved: http://www.compositemodeling.com

Henseler, J., Ray, P.A., \& Hubona, G. (2016). Using PLS path modeling in new technology research: updated guidelines. Industrial Management \& Data Systems, 116(1), 2-20.

Henseler, J., Ringle, C.M., \& Sarstedt, M. (2015). A new criterion for assessing discriminant validity in variance-based structural equation modeling. Journal of the Academy of Marketing Science, 43(1), 115-135.

Hewer, P., Gannon, M., \& Cordina, R. (2017). Discordant fandom and global football brands:'Let the people sing'. Journal of Consumer Culture, 17(3), 600-619.

Jafari, A., Taheri, B., \& vom Lehn, D. (2013). Cultural consumption, interactive sociality, and the museum. Journal of Marketing Management, 29(15-16), 1729-1752.

Jin, N., Line, N.D., \& Merkebu, J. (2016). The impact of brand prestige on trust, perceived risk, satisfaction, and loyalty in upscale restaurants. Journal of Hospitality Marketing \& Management, 25(5), 523-546.

Kantsperger, R., \& Kunz, W.H. (2010). Consumer trust in service companies: a multiple mediating analysis. Managing Service Quality: An International Journal, 20(1), 4-25.

Kesgin, M., \& Murthy, R.S. (2019). Consumer engagement: The role of social currency in online reviews. Service Industries Journal, 39(7-8), 609-636.

Khodyakov, D. (2007). Trust as a process: A three-dimensional ppproach. Sociology, 41(1), 115-132.

Knutson, B.J., Kim, S., Beck, J.A., \& Cha, J. (2011). Development and testing of the consumer experience index (CEI). Managing Service Quality: An International Journal, 21(2), 112132.

Kolar, T., \& Zabkar, V. (2010). A consumer-based model of authenticity: An oxymoron or the foundation of cultural heritage marketing? Tourism Management, 31(5), 652-664.

Kroeger, F. (2012). Trusting organizations: The institutionalization of trust in interorganizational relationships. Organization, 19(6), 743-763.

Lane, M. (2007). The visitor journey: the new road to success. International Journal of Contemporary Hospitality Management, 19(3), 248-254.

Lechner, A. T., \& Paul, M. (2019). Is this smile for real? The role of affect and thinking style in customer perceptions of frontline employee emotion authenticity. Journal of Business Research, 94, 195-208.

Lee, Y.-J. (2015). Creating memorable experiences in a reuse heritage site. Annals of Tourism Research, 55(2015), 155-170.

Lewicki, R.J., Tomlinson, E.C., \& Gillespie, N. (2006). Models of interpersonal trust development: Theoretical approaches, empirical evidence, and future directions. Journal of Management, 32(6), 991-1022.

Liang, H., Saraf, N., Hu, Q., \& Xue, Y. (2007). Assimilation of enterprise systems: The effect of institutional pressures and the mediating role of top management. MIS Quarterly, 31(1), 5987.

Liébana-Cabanillas, F., Alonso-Dos-Santos, M., Soto-Fuentes, Y., \& Valderrama-Palma, V.A. (2017). Unobserved heterogeneity and the importance of customer loyalty in mobile banking. Technology Analysis \& Strategic Management, 29(9), 1015-1032.

Lochrie, S. (2016). Engaging and marketing to stakeholders in world heritage site management: a UK multiple case study perspective. Journal of Marketing Management, 32(15-16), 1392-1418.

Lochrie, S., Baxter, I.W., Collinson, E.,...\& Yalinay, O. (2019). Self-expression and play: can religious tourism be hedonistic?. Tourism Recreation Research, 44(1), 2-16.

Lovell, G. (2009). Can I trust you? An exploration of the role of trust in hospitality service settings. Tourism and Hospitality Planning \& Development, 6(2), 145-157. 
Lude, M., \& Prügl, R. (2018). Why the family business brand matters: Brand authenticity and the family firm trust inference. Journal of Business Research, 89, 121-134.

MacKenzie, N., \& Gannon, M.J. (2019). Exploring the antecedents of sustainable tourism development. International Journal of Contemporary Hospitality Management. DOI: 10.1108/IJCHM-05-2018-0384.

Marinao Artigas, E., Yrigoyen, C.C., Moraga, E.T., \& Villalón, C.B. (2017). Determinants of trust towards tourist destinations. Journal of Destination Marketing \& Management, 6(4), 327334.

Mayer, R.C., Davis, J.H., \& Schoorman, F.D. (1995). An integrative model of organizational trust. Academy of Management Review, 20(3), 709-734.

McKnight, D.H., Choudhury, V., \& Kacmar, C. (2002). The impact of initial consumer trust on intentions to transact with a web site: a trust building model. The Journal of Strategic Information Systems, 11(3), 297-323.

Merchant, A., \& Rose, G.M. (2013). Effects of advertising-evoked vicarious nostalgia on brand heritage. Journal of Business Research, 66(12), 2619-2625.

Moorman, C., Zaltman, G., \& Deshpande, R. (1992). Relationships between providers and users of market research: The dynamics of trust within and between organizations. Journal of Marketing Research, 29(3), 314-328.

Napoli, J., Dickinson, S.J., Beverland, M.B., \& Farrelly, F. (2014). Measuring consumer-based brand authenticity. Journal of Business Research, 67(6), 1090-1098.

Navrud, S., \& Ready, R.C. (2002). Valuing cultural heritage: Applying environmental valuation techniques to historic buildings, monuments and artefacts. Cheltenham, UK: Edward Elgar.

Newton, K. (2001). Trust, social capital, civil society, and democracy. International Political Science Review, 22(2), 201-214.

Podsakoff, P. M., MacKenzie, S.B., Lee, J.-Y., \& Podsakoff, N.P. (2003). Common method biases in behavioral research: A critical review of the literature and recommended remedies. Journal of Applied Psychology, 88(5), 879-903.

Ponnapureddy, S., Priskin, J., Ohnmacht, T., Vinzenz, F., \& Wirth, W. (2017). The influence of trust perceptions on German tourists' intention to book a sustainable hotel. Journal of Sustainable Tourism, 25(7), 970-988.

Prince, S. (2017). Working towards sincere encounters in volunteer tourism: an ethnographic examination of key management issues at a Nordic eco-village. Journal of Sustainable Tourism, 25(11), 1617-1632. .

Rasoolimanesh, M., Taheri, B., Gannon, M., Vafaei-Zadeh, A. \& Hanifah, H. (2019). Does living in the vicinity of heritage tourism sites influence residents' perceptions and attitudes? Journal of Sustainable Tourism. Doi: 10.1080/09669582.2019.1618863.

Robbins, B.G. (2016). What is trust? A multidisciplinary review, critique, and synthesis. Sociology Compass, 10(10), 972-986.

Rose, G.M., Merchant, A., Orth, U.R., \& Horstmann, F. (2016). Emphasizing brand heritage: Does it work? And how? Journal of Business Research, 69(2), 936-943.

Rotter, J.B. (1967). A new scale for the measurement of interpersonal trust1. Journal of Personality, 35(4), 651-665.

Rousseau, D.M., Sitkin, S.B., Burt, R.S., \& Camerer, C. (1998). Not so different after all: A crossdiscipline view of trust. Academy of Management Review, 23(3), 393-404.

Sabel, C.F. (1993). Studied trust: Building new forms of cooperation in a volatile economy. Human Relations, 46(9), 1133-1170.

Simintiras, AC., Yeniaras, V., Oney, E., \& Bahia, T.K. (2014). Redefining confidence for consumer behavior research. Psychology \& Marketing, 31(6), 426-439.

Simon, N. (2010). The Participatory Museum. Santa Cruz, California: Museum 2.0.

Sirdeshmukh, D., Singh, J., \& Sabol, B. (2002). Consumer trust, value, and loyalty in relational exchanges. Journal of Marketing, 66(1), 15-37.

Steiner, C.J., \& Reisinger, Y. (2006). Understanding existential authenticity. Annals of Tourism Research, 33(2), 299-318.

Taheri, B., Bititici, U., Gannon, M.J. \& Cordina, R. (2019). Investigating the influence of performance measurement on learning, entrepreneurial orientation and performance in 
turbulent markets. International Journal of Contemporary Hospitality Management. 31(3), 1224-1246.

Taheri, B., Gannon, M.J., Cordina, R. \& Lochrie, S. (2018). Measuring host sincerity: scale development and validation. International Journal of Contemporary Hospitality Management, 30(8), 2752-2772.

Taheri, B., Jafari, A., \& Okumus, B. (2017). Ceremonious politeness in consuming food in VFR tourism: scale development. Service Industries Journal, 37(15-16), 948-967.

Tellström, R., Gustafsson, I.-B., \& Mossberg, L. (2006). Consuming heritage: The use of local food culture in branding. Place Branding, 2(2), 130-143.

Thompson, J., Baxter, I.W.F., Curran, R., Gannon, M.J.,...\& Yalinay, O. (2018). Negotiation, bargaining, and discounts: generating WoM and local tourism development at the Tabriz bazaar, Iran. Current Issues in Tourism, 21(11), 1207-1214.

UNESCO. (2017). What is meant by "cultural heritage"? UNESCO Online. Retrieved 26/10/2017: http://www.unesco.org/new/en/culture/themes/illicit-trafficking-of-cultural-property/unescodatabase-of-national-cultural-heritage-laws/frequently-asked-questions/definition-of-thecultural-heritage/

Wang, L., Law, R., Hung, K., \& Guillet, B.D. (2014). Consumer trust in tourism and hospitality: A review of the literature. Journal of Hospitality and Tourism Management, 21, 1-9.

Wang, S.W., Ngamsiriudom, W., \& Hsieh, C.H. (2015). Trust disposition, trust antecedents, trust, and behavioral intention. Service Industries Journal, 35(10), 555-572.

Ward, P., \& Meyer, S. (2009). Trust, social quality and wellbeing: A sociological exegesis. Development and Society, 38(2), 339-363.

Wu, H.C. (2017). What drives experiential loyalty? A case study of Starbucks coffee chain in Taiwan. British Food Journal, 119(3), 468-496.

Yalinay, O., Baxter, I.W.F., Collinson, E., Curran, R.,...\& Thompson, J. (2018). Servicescape and shopping value: the role of negotiation intention, social orientation, and recreational identity at Istanbul Grand Bazaar, Turkey. Journal of Travel \& Tourism Marketing, 35(9), 11321144.

Yang, S.B., Lee, K., Lee, H., \& Koo, C. (2018). In Airbnb we trust: Understanding consumers' trustattachment building mechanisms in the sharing economy. International Journal of Hospitality Management. doi:10.1016/j.ijhm.2018.10.016.

Ye, S., Xiao, H., \& Zhou, L. (2018). Commodification and perceived authenticity in commercial homes. Annals of Tourism Research, 71, 39-53. 


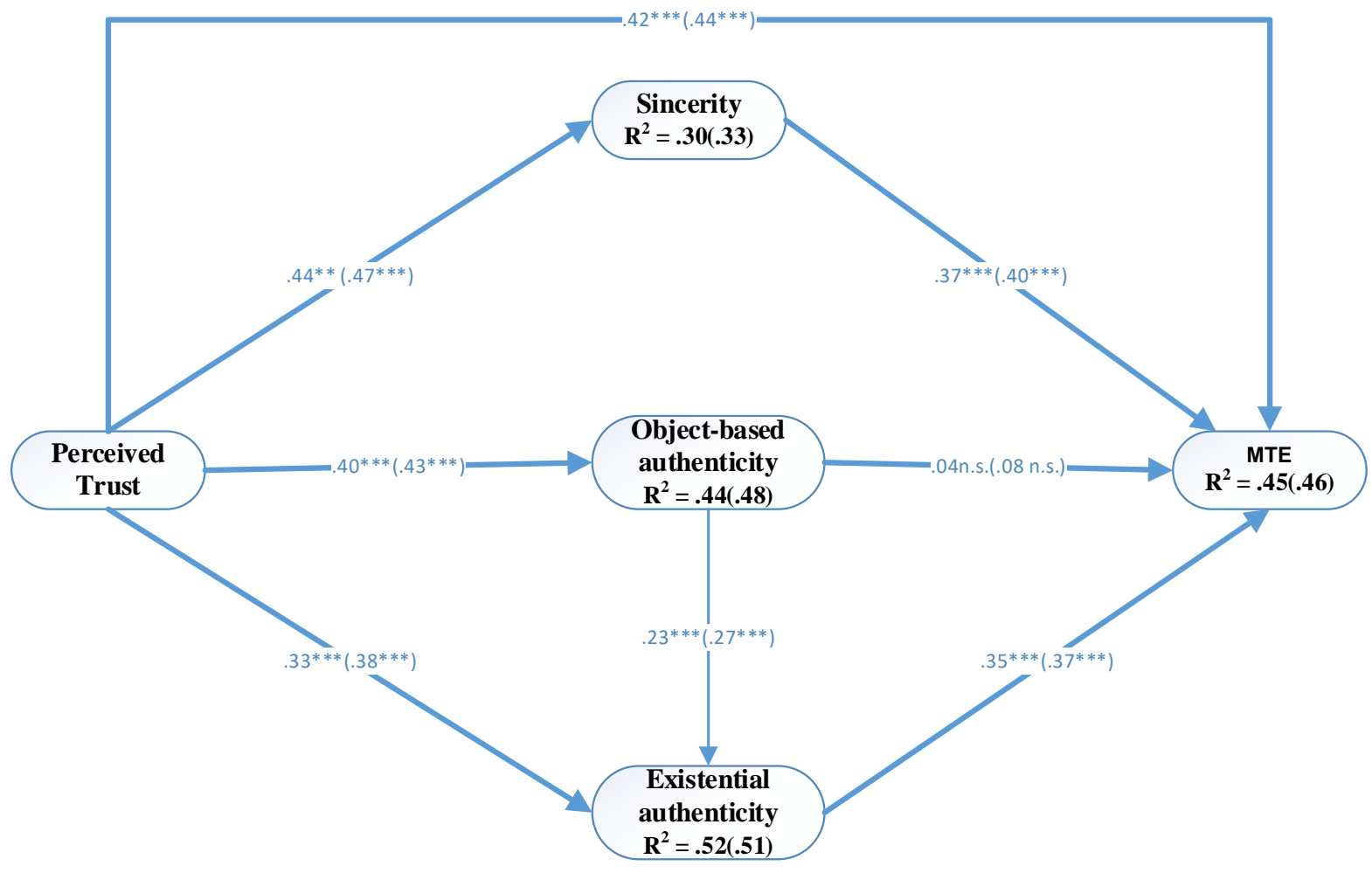

Figure 1.Research model 
Table 1.Multidisciplinary definitions of trust

\begin{tabular}{|c|c|c|c|}
\hline Source & Discipline & Explanation & See also \\
\hline $\begin{array}{l}\text { (Caton et al., } \\
\text { 2012, p.428) }\end{array}$ & $\begin{array}{l}\text { Computer } \\
\text { science }\end{array}$ & $\begin{array}{l}\text { “...positive expectation or assumption on future } \\
\text { outcomes that results from proven } \\
\text { contextualised personal interaction-histories } \\
\text { corresponding to conventional relationship } \\
\text { types and can be leveraged by formal and } \\
\text { informal rules and conventions within a Social } \\
\text { Cloud to facilitate as well as influence the scope } \\
\text { of collaborative exchange.” }\end{array}$ & (Al Qundus et al., 2019) \\
\hline $\begin{array}{l}\text { (Sabel, } \\
\text { 1993, } \\
\text { p.1133) }\end{array}$ & Economics & $\begin{array}{l}\text { "...the mutual confidence that no party to an } \\
\text { exchange will exploit the other's vulnerability." }\end{array}$ & (Evans \& Krueger, 2009) \\
\hline $\begin{array}{l}\text { (Mayer et } \\
\text { al., } 1995 \text {, } \\
\text { p.712) }\end{array}$ & Management & $\begin{array}{l}\text { "...the willingness of a party to be vulnerable to } \\
\text { the actions of another party based on the } \\
\text { expectation that the other will perform a } \\
\text { particular action important to the trustor, } \\
\text { irrespective of the ability to monitor or control } \\
\text { that other party." }\end{array}$ & $\begin{array}{l}\text { (Lewicki, Tomlinson, } \\
\text { Gillespie, 2006) }\end{array}$ \\
\hline $\begin{array}{l}\text { (Moorman et } \\
\text { al., 1992, } \\
\text { p.314) }\end{array}$ & Marketing & $\begin{array}{l}\text { “...willingness to rely on an exchange partner in } \\
\text { whom one has confidence.” }\end{array}$ & $\begin{array}{l}\text { (Kantsperger \& Kunz, 2010; } \\
\text { Sirdeshmukh et al., 2002) }\end{array}$ \\
\hline $\begin{array}{l}\text { (Kroeger, } \\
\text { 2012, p.747) }\end{array}$ & $\begin{array}{l}\text { Organizational } \\
\text { science }\end{array}$ & $\begin{array}{l}\text { "an actor who trusts an organization makes } \\
\text { themselves vulnerable to the actions of others } \\
\text { who are guided by the organization, based on } \\
\text { what the actor knows about the regularities of } \\
\text { organizational behavior and about the } \\
\text { behavioural incentives and norms as set by the } \\
\text { organization" }\end{array}$ & $\begin{array}{l}\text { (Fulmer \& Gelfand, 2012; } \\
\text { Rousseau et al., 1998) }\end{array}$ \\
\hline $\begin{array}{l}\text { (Newton, } \\
2001, \text { p.202) }\end{array}$ & $\begin{array}{l}\text { Political } \\
\text { Science }\end{array}$ & $\begin{array}{l}\text { “...the actor's belief that, at worst, others will } \\
\text { not knowingly or willingly do him harm, and at } \\
\text { best, that they will act in his interests”. }\end{array}$ & (Enli \& Rosenberg, 2018) \\
\hline $\begin{array}{l}\text { (Gidman et } \\
\text { al., 2012, } \\
\text { p.2) }\end{array}$ & Public health & $\begin{array}{l}\text { "...optimistic acceptance of a vulnerable } \\
\text { situation which is based on positive } \\
\text { expectations of the intentions of the trusted } \\
\text { individual or institution" }\end{array}$ & (Ward \& Meyer, 2009) \\
\hline $\begin{array}{l}\text { (Rotter, } \\
\text { 1967, p.651) }\end{array}$ & $\begin{array}{l}\text { Social } \\
\text { psychology }\end{array}$ & $\begin{array}{l}\text { "Expectancy held by an individual or group that } \\
\text { the word, promise, verbal or written statement } \\
\text { of another...can be relied upon." }\end{array}$ & (Evans \& Krueger, 2009) \\
\hline $\begin{array}{l}\text { (Khodyakov, } \\
\text { 2007, p.126) }\end{array}$ & Sociology & $\begin{array}{l}\text { "...a process of constant imaginative } \\
\text { anticipation of the reliability of the other party's } \\
\text { actions based on (1) the reputation of the partner } \\
\text { and the actor, ( } 2 \text { ) the evaluation of current } \\
\text { circumstances of action, (3) assumptions about } \\
\text { the partner's actions, and (4) the belief in the } \\
\text { honesty and morality of the other side." }\end{array}$ & (Robbins, 2016) \\
\hline
\end{tabular}


Table 2.Survey items and descriptive statistics

\begin{tabular}{|c|c|c|}
\hline Constructs/Associated items & Mean & Std. Deviation \\
\hline \multicolumn{3}{|l|}{ Sincere social interaction(Taheri et al., 2018) } \\
\hline $\begin{array}{l}\text { My interactions with locals help to reinforce my understanding of the } \\
\text { place }\end{array}$ & 5.89 & 1.182 \\
\hline Locals are eager to educate me with regards to their culture & 5.03 & 1.81 \\
\hline I talk and interact with locals about their real and true culture & 5.34 & 2.12 \\
\hline Locals are happy to involve me in their real lives & 4.92 & 1.92 \\
\hline Locals are comfortable showing me their culture & 4.77 & 1.79 \\
\hline \multicolumn{3}{|l|}{ Sincere emotional response(Taheri et al., 2018) } \\
\hline It is important that I see the real lives of locals. & 5.83 & 1.64 \\
\hline When I see locals, I am conscious of their role within the place. & 4.12 & 1.25 \\
\hline Locals present themselves to visitors/guests accurately and honestly. & 5.17 & 1.64 \\
\hline $\begin{array}{l}\text { There are similarities between what I see and my expectations of } \\
\text { locals }\end{array}$ & 4.06 & 1.25 \\
\hline Locals represent themselves truthfully and passionately to visitors & 5.09 & 1.55 \\
\hline \multicolumn{3}{|l|}{ Object-based authenticity(Bryce et al., 2015; Kolar \& Zabkar, 2010) } \\
\hline The overall architecture and impression inspired me & 3.40 & 1.95 \\
\hline I liked the design and tangible elements within the site & 3.57 & 1.76 \\
\hline $\begin{array}{l}\text { I liked the way the site blends with the wider environment, which } \\
\text { offers many other interesting places for sightseeing }\end{array}$ & 3.49 & 1.86 \\
\hline I liked the information provided within the site and found it interesting & 3.91 & 1.69 \\
\hline \multicolumn{3}{|l|}{ Existential authenticity(Bryce et al., 2015; Kolar \& Zabkar, 2010) } \\
\hline I liked special arrangements, events, celebrations connected to the site. & 3.50 & 2.03 \\
\hline This visit provided a thorough insight into the specific historical era. & 3.72 & 2.06 \\
\hline $\begin{array}{l}\text { During the visit I felt the related history, legends, and historical } \\
\text { personalities }\end{array}$ & 3.76 & 2.19 \\
\hline I enjoyed the unique spiritual experience & 3.13 & 2.18 \\
\hline I liked the calm and peaceful atmosphere during the visit & 3.85 & 1.77 \\
\hline I felt connected with human history and civilization & 4.02 & 1.80 \\
\hline \multicolumn{3}{|l|}{ MTE(Lee, 2015) } \\
\hline I enjoyed this experience and feel excited & 5.40 & 1.95 \\
\hline I closely experienced the local culture & 5.57 & 1.76 \\
\hline I enjoyed a sense of freedom & 5.49 & 1.86 \\
\hline I did something meaningful & 5.91 & 1.69 \\
\hline I gained a lot of knowledge about this place & 5.08 & 2.07 \\
\hline
\end{tabular}


Table 3.Summary of measurement model assessment

\begin{tabular}{llllllll}
\hline Construct & $\begin{array}{l}\text { Loading } \\
(\mathrm{PLS})\end{array}$ & $\begin{array}{l}\text { Loading } \\
(\mathrm{PLSC})\end{array}$ & CR & AVE & $\rho_{\mathrm{A}}$ & $\rho_{\mathrm{C}}$ & $\begin{array}{l}\text { Max } \\
\text { HTMT }\end{array}$ \\
\hline Trust & {$[.76,82]$} & {$[.72, .839]$} & .91 & .60 & .87 & .74 & .32 \\
Object-based authenticity & {$[.70, .80]$} & {$[.72, .82]$} & .85 & .52 & .81 & .77 & .45 \\
Existential authenticity & {$[.71, .80]$} & {$[.72, .82]$} & .87 & .51 & .82 & .84 & .44 \\
MTE & {$[.71, .87]$} & {$[.71, .81]$} & .86 & .58 & .83 & .76 & .61 \\
Sincere social interaction & {$[.72, .82]$} & {$[.72, .82]$} & .82 & .61 & .84 & .81 & .58 \\
Sincere emotional response & {$[.71, .83]$} & {$[.72, .83]$} & .80 & .57 & .88 & .83 & .51 \\
\hline
\end{tabular}

Note: Dijkstra-Henseler's $\rho_{\mathrm{A}}>.70 ; \quad$ Dillon-Goldstein's $\rho_{\mathrm{C}}>.70 ;$ Composite reliability $(\mathrm{CR})>.70$; Average Variance Extracted (AVE)>.50; heterotrait-monotrait ratio of correlations (HTMT)>0.85; Loading>.60.

Table 4.Correlation Matrix

\begin{tabular}{llllllll}
\hline & $(1)$ & $(2)$ & $(3)$ & $(4)$ & $(5)$ & $(6)$ & $(7)$ \\
\hline (1)Trust & .77 & & & & & & \\
(2)Object-based authenticity & .48 & .72 & & & & & \\
(3)Existential authenticity & .16 & .43 & .71 & & & & \\
(4)Sincerity & .45 & .26 & .31 & $\mathbf{n} / \mathbf{a}$ & & & \\
(5)MTE & .38 & .43 & .37 & .45 & .76 & & \\
(6)Sincere social interaction & .42 & .35 & .23 & .29 & .33 & .78 & \\
(7)Sincere emotional response & .32 & .32 & .47 & .54 & .28 & .23 & .75 \\
\hline
\end{tabular}

Note: 'Sincerity' AVE value is absent as sincerity was specified as a higher-order model; square root of AVE is diagonal in boldface. Inter-construct correlation is shown off the diagonal; $\mathrm{n} / \mathrm{a}=$ not applicable.

Table 5.Correlation between sincerity dimensions, trust, and MTE

\begin{tabular}{llll}
\hline Dimensions & Correlations & Lower bound CI & Higher bound CI \\
\hline Trust $<->$ Sincere social interaction & $.32^{*}$ & .24 & .39 \\
Trust $<->$ Sincere emotional response & $.40^{*}$ & .32 & .47 \\
MTE $<->$ Sincere social interaction & $.34^{*}$ & .27 & .41 \\
MTE $<->$ Sincere emotional response & $.28^{*}$ & .22 & .35 \\
\hline
\end{tabular}

Note: Significant at $* t>3.29 ; p<.001 ;$ n.s. $=$ non-significant. $\mathrm{CI}=$ confidence interval. 